\section{Commentary: If I could be like Mike}

\author{
David L. Joyce, MD, MBA, FACS
}

Kenneth Morse, founder of the Massachusetts Institute of Technology Entrepreneurship Center, famously described innovation as invention plus commercialization. In a comprehensive review, Hanke and colleages ${ }^{1}$ have expanded this definition to include the Henderson and Clark $^{2}$ framework, which emphasizes the disruptive potential of incremental innovation within a given industry. When applied to the field of mechanical circulatory support, disruptive innovation encompasses priorities such as miniaturization, fully implantable technology, and improved instrumentation. It is impossible to reflect on the progress that has been made toward these goals without considering the legacy of Michael Ellis DeBakey.

Throughout his career, DeBakey dominated all 4 quadrants of the Hanke framework: basic research, breakthrough innovation, sustaining innovation, and disruptive innovation. ${ }^{3}$ There have been no recent improvements in surgical instrumentation that have had the lasting influence of the forceps that bear his name (also known as magics to members of the Shumway sect). His vision for a fully implantable total artificial heart, although not yet realized, was brought within reach thanks to strides that were made in miniaturization when he partnered with NASA engineers to champion the idea of axial flow. ${ }^{4}$ In a Grand Rounds presentation in 2004, DeBakey pointed out the advantages of having practiced at a time when the terms Food and Drug Administration and institutional review board had not yet found their way into discussions on the approval of medical devices. Looking to the future, it is clear that the current

\footnotetext{
From the Department of Surgery, Medical College of Wisconsin, Milwaukee, Wis. Disclosures: The author reported no conflicts of interest.

The Journal policy requires editors and reviewers to disclose conflicts of interest and to decline handling or reviewing manuscripts for which they may have a conflict of interest. The editors and reviewers of this article have no conflicts of interest.

Received for publication Oct 7, 2021; revisions received Oct 7, 2021; accepted for publication Oct 15, 2021; available ahead of print Oct 29, 2021.

Address for reprints: David L. Joyce, MD, MBA, FACS, Hub for Collabortative Medicine, 8701 Watertown Plank Rd, Milwaukee, WI 53226 (E-mail: djoyce@mcw. edu).

JTCVS Open 2021;8:35-6

2666-2736

Copyright (c) 2021 The Author(s). Published by Elsevier Inc. on behalf of The American Association for Thoracic Surgery. This is an open access article under the CC BY-NC-ND license (http://creativecommons.org/licenses/by-nc-nd/4.0/).

https://doi.org/10.1016/j.xjon.2021.10.009
}

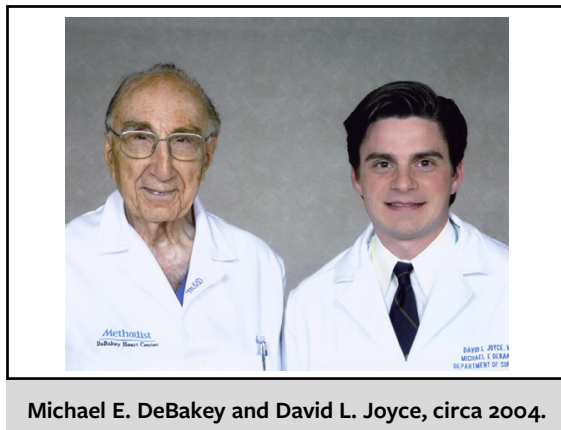

CENTRAL MESSAGE

Innovation and regulation are interdependent features of medical progress.

regulatory environment has influenced both the pace and direction of innovation.

As an example, left ventricular assist device explantation can be greatly facilitated by the use of a customized titanium plug. After gaining approval from the Food and Drug Administration to implant this technology on a small number of patients as compassionate use, our team ultimately abandoned the approach in favor of outflow graft defunctionalization due to the prohibitive expenses involved in pursuing investigational device exemption. It remains to be established which of these 2 approaches offers the safest option for patients, illustrating the 2 different standards that exist depending on whether innovation occurs in the form of a medical device or a surgical procedure.

There are 2 lessons to be found in this paradox. The first is that peer review should always accompany daring new surgical maneuvers. Scientific journals should feature a section that highlights strategies that failed, not just the exceptional case reports where adding a robot to the equation actually worked. Second, surgeons of the 21st century should emulate the example of DeBakey, whose advocacy efforts on Capitol Hill were fundamental to the progress that has been made in the realm of mechanical circulatory support. When it comes to regulatory reform, leadership will save more lives than resentment.

\section{References}

1. Hanke JS, Dogan G, Shrestha M, Haverich A, Schmitto JD. Innovations in implantation techniques of ventricular assist devices. J Thorac Cardiovasc Surg Open. 2021;8:28-32.

2. Clark KB, Henderson RM. Architectural innovation: the reconfiguration of existing product technologies and the failure of established firms. Admin Sci Q. 1990; 35:9-30. 
3. Joyce LD, Noon GP, Joyce DL, DeBakey ME. Mechanical circulatory support-a historical review. ASAIO J. 2004;50:x-xii. https://doi.org/10.1097/01.mat. 0000151682.27833 .30
4. Debakey ME. The odyssey of the artificial heart. Artif Organs. 2000;24:405-11. https://doi.org/10.1046/j.1525-1594.2000.06635.x 